\title{
416 Book reviews
}

The writers of these papers have had to describe extremely complex research work, avoid over-simplification lest a point be lost, and also to condense. No wonder the reading is toilsome. But let no one suppose, as they might from the title of the book, that this is just a primer of development from birth to one year. It is a book by psychologists for other psychologists and they are not talking down to anyone.

DERMOD MACCARTHY

A Reference Manual of Growth and Development. By J M H Buckler. (Pp. 104; illustrated + tables. $£ 5.50$ hardback.) Blackwell Scientific: Oxford. 1979.

Since the accurate assessment of growth and development is fundamental to the trade, most paediatricians carry with them more or less stained and dog-eared folders of growth charts and aidesmemoire to development. It was an excellent idea, therefore, to collect the most useful of these in compact book form. The value of the book rests on the selection of data and the quality of reproduction. Fortunately the TannerWhitehouse growth data are indisputably the best available for English children and their bi-acromial and bi-iliac diameters, skinfold thickness, pubertal development, and prediction of adult height are included. In addition there are norms for surface area, dental development, embryonic development, gestational age assessments, developmental assessment, ventilatory function, ECGs, kidney size, and urine volume. Each section is introduced briefly. Inevitably, each reader will regret some omissions (why is the Denver Developmental Screening Test described but not illustrated?), and inclusions (are these bone age illustrations of real use?), but to me, the selection seems eminently sensible and balanced. Because of the restriction imposed by the page size, the reproduction of some of the charts is not as clear or as detailed as the originals but it is always adequate. Few paediatricians, GPs, and others concerned with growth and development in children would fail to benefit from the presence of this useful little book beside them as they work.

N D BARNES

Secretory Otitis Media and its Sequelae. Monographs in Clinical Otolaryngology, vol. 1. By Jacob Sadé. (Pp. 321; illustrated + tables. $£ 19.50$ hardback.) Churchill Livingstone: Edinburgh. 1979.

It is a pleasure to review this excellent and valuable book. The subject, known in this country as 'glue ear', is a condition so common that no person who comes in contact with children-whether GP, ENT surgeon, paediatrician, or indeed audiologist, speech therapist, or teacher-can avoid meeting it frequently. Despite this continuous contact, there are few subjects that attract more questions to the specialist, more invitations to lecture, and more concern from parents.

Professor Sadé, who has edited this book, has also written most of the chapters. He has studied this field for many years and his contributions have always been valuable, so it is as a wellrecognised expert that he brings all that is known together in this way. He covers the clinical and experimental field in a masterly manner and introduces throughout an original touch which excites the imagination. In asking Professors Tos, Lim, Bernstein, Silberberg, and Dolan to write special chapters he has covered the fields of histology, microbiology, immunology, biochemistry, and radiolo in a manner more complete than ever before. Each writer is an expert $\overrightarrow{f r}$ considerable stature and adds enormousiy to the value of the book. Professor Me Bergnan, with his vast experience both America and Israel, writes a clear ared up-to-date chapter on the audiology of this condition which should be read everyone who carries out tests affel interprets them.

My only regret is that Professor Sadé did not also include a chapter on t $\overrightarrow{g e}$ accumulating, if recent, knowledge on tRe linguistic and educational problems of the children who suffer from this commof condition. These are less often described and less well known and it would have been useful to find them in what is perfect book.

The publishers announce further monographs in this series and if they are all of this exceptional standard they are to be warmly thanked.

\section{Shorter notice}

Anticonvulsant Therapy. Pharmacologic Basis and Practice. Second edition. Mervyn J Eadie and John H Tyrê. (Pp. 338; illustrated + tables. $£ 17$. hardback.) Churchill Livingstone Edinburgh. 1980.

Knowledge of clinical pharmacology becoming increasingly important in practical patient management, and in field is this more true than in the use of anticonvulsants. This is a useful soure book on the pharmacokinetics, mode of action, and unwanted effects of the commonly used anticonvulsants. Not textbook of epilepsy, but a useful book for those who treat it. 